\title{
Attitude Assessment of young MBBS Doctors towards Compulsory Rural Bond
}

\author{
Authors \\ Dr Priyanka Mahawar ${ }^{1}$, Dr Priyanka Bhaskar ${ }^{2 *}$, Dr Salil Sakalle ${ }^{3}$, \\ Dr Sanjay Dixit ${ }^{4}$, Dr Akansha Kalra ${ }^{2}$ \\ ${ }^{1}$ Associate Professor, ${ }^{2}$ PG Resident, ${ }^{3}$ Professor, ${ }^{4}$ Professor \& HOD \\ Department of community medicine, M.G.M. Medical College Indore (M.P.) \\ *Corresponding Author \\ Dr Priyanka Bhaskar
}

PG Resident, Department of community medicine, M.G.M. Medical College Indore (M.P.), India

\begin{abstract}
Background: Health sector in India faces multiple challenges due to the disparate geographic distribution of human resources. National Rural Health Mission is facing several constraints; one of which is the lack of human resources, especially doctors ready to work in the rural areas.

Aims \& Objectives 1) To assess views of medical student towards rural bond service,

2) To assess knowledge regarding benefits, extension \& exemption of rural bond service,

Material \& Methods: The present study is a cross sectional study, conducted in the randomly selected 140 MBBS Students of pre-final, final and internship batch in MGM Medical College, Indore for 4 month. Written Informed consent was to be taken from the students. The study tool of the study is Pre Designed semi structured Questionnaire, Data was entered in excel sheet and analyzed using SPSS Software, appropriate statistical test was applied wherever necessary.

Results: In our study it was found that 111(79.28 \%) students visited clinical posting daily with attendance of $>75 \%$. 96(68.57\%) students found themselves capable of running a PHC, 121(87.12\%) were willing to complete the bond after completing MBBS,102 (72.85\%) of students have knowledge about the benefits of rural bond,129(92.14\%) students were willing to complete the rural bond if posted in area of their choice, 121 (86.42\%) students agree that the reason for extension and exemption is P.G. preparation.

Conclusion: As rural health is suffering from lack of health facilities so students should be posted in rural area for some time during their MBBS so they get sensitized to the rural health problem.

Keywords: Students, rural bond, MBBS.
\end{abstract}

\section{Introduction}

Health sector in India faces multiple challenges due to the disparate geographic distribution of human resources. National Rural Health Mission is facing several constraints; one of which is the lack of human resources, especially doctors ready to work in the rural areas. There is skewed distribution of people working in rural urban areas. In India every year 40,000 allopathic doctors are produced from 335 medical colleges 
recognized by the Medical Council of India, but most of them prefer to practice in urban areas. There is a deficit of about 2866 (12\%) MBBS doctors in the PHCs, the requirement being 23,887. ${ }^{1}$ Government of India thus introduced the concept of Rural Bond. The views and perception toward rural health care of such budding doctors is therefore necessary to consider. This will assist in identifying strategies to increase the quality and quantity of healthcare human resources available to underserved regions of the nation.

After completing internship, students of the MBBS must spend 12 months in rural practice four months each in a primary health centre, a community health centre and a district hospital. Only after these rural services they will be awarded an MBBS degree., ${ }^{2,3}$

The aim of study is to assess views of medical student toward rural bond service, to assess knowledge regarding benefits of rural bond service, and extension \& exemption of rural bond.

\section{Methodology}

The present study is a cross-sectional study carried during one academic year of MBBS student in Indore from Sept 2017 to Dec 2017. Two batches of MBBS final year and internship batch were chosen, there are 140 students in a batch. Random sampling technique using attendance register .Every second student was taken, thus 140 were selected. Appropriate Permission was taken from the concerned authority .In our study MBBS Student of MGM Medical College Indore, are included and Students of MGM Medical College Indore, who are perceiving other courses were excluded. Informed consent in written was to be taken from the participants. All the information collected through the questionnaire is kept confidential .The study tool of the study is Pre Designed semi structured Questionnaire Then Collection and Compilation of data, after that Analysis and Interpretation of data, Data was entered in Microsoft Excel sheet and analyzed using SPSS Software, and appropriate statistical test was applied wherever necessary.

\section{Results}

In our study it was found that $111(79.28 \%)$ students visited clinical posting daily with attendance of $>75 \%$. 96(68.57\%) students found themselves capable of running a PHC. Majority $117(83.57 \%)$ students wanted to go for Post Graduate preparation after completing MBBS, $68(48.57 \%)$ students would have filled the rural bond if it was not compulsory.

All the students know about duration of rural service bond, $82(58.57 \%)$ filled rural bond of 3 lakhs at the time of admission, 121(87.12\%) were willing to complete the bond after completing MBBS,102 (72.85\%) of students have knowledge about the benefits of rural bond,129(92.14\%) students were willing to complete the rural bond if posted in area of their choice,140(100\%) of the students agree that rural service bond is important as doctor to patient ratio is very low in our country, beneficial to get sensitized to rural health problems in our country and it develops a sense of social responsibility among medical students.

$138(98.57 \%)$ students agree that rural bond is beneficial because still health services are not available in many hard to reach areas, 46(32.85 $\%$ ) students had knowledge about the extension of bond and 29(20.71\%) students knew about the procedure of extension, $40(28.57 \%)$ students knew about the procedure of exemption.

$121(86.42 \%)$ students agree that the reason for extension and exemption is P.G. preparation,32 $(22.85 \%)$ students were willing to go for rural service after P.G. in case they opted, 55 (39.28\%) agreed upon no basic facilities for doctors and unavailability of diagnostic tool and staff as other probable reason not to go for rural service, $40(28.57 \%)$ students agree with the government proposal in making the rural bond mandatory with no option for exemption,122(87.14\%) students think that by making rural bond mandatory the primary health service will improve. 


\section{Discussion}

This study was done to understand the career choices of would-be-graduates of medical schools and their interest in working in public health system particularly in the rural areas and knowledge about the extension and exemption from rural bond. Altogether, 140 students from MGM Medical, college participate in the study.

In our study it was found that 111(79.28 \%) students visited clinical posting daily with attendance of $>75 \%$. 96(68.57\%) students found themselves capable of running a PHC. It was concluded that students who visited clinical posting regularly find themselves capable enough to run $\mathrm{PHC}$.

In our study 121(86.42\%) majority of students preferred aim was to get into PG and similar results were found in previous study done in medical colleges of Karnataka, Odisha. This has critical implication for primary health care. We also found that after completing PG, students do not want to go to rural area for posting. A study conducted in India revealed that undergraduate medical students preferred to do PG course because they felt that they could not manage patients with the inadequate knowledge they acquired as undergraduates. ${ }^{4}$ Medical educationists have advocated rural medical schools as a strategy to address the growing unwillingness of students for rural medical careers.

Accordingly, countries like Australia have started rural clinical schools. ${ }^{5}$ these schools are expected to produce physicians who are sensitive to the health care needs of the rural community and interested in working in those settings. Unless similar efforts are made in India to divert a considerable proportion of future physicians to the rural areas, they would simply be stationed in urban settings, which will still militate against meeting the current deficit of rural physicians. ${ }^{6}$ We also found that a reason for non-willingness is because they think that there is lack of infrastructural facilities in health centre. This is corroborated with other findings in previous studies. $^{7,8,9 \text {, }}$

Majority of students $121(87.12 \%)$ were willing to complete the bond after completing MBBS, 102 (72.85\%) students have knowledge about the benefits of rural bond. It was found that $129(92.14 \%)$ students were willing to complete the rural bond if posted in area of their choice thus a preference off home town should be given to all students before allotting them a PHC.140(100\%) of the students agree that rural service bond is important as doctor to patient ratio is very low in our country, beneficial to get sensitized to rural health problems in our country and it develops a sense of social responsibility among medical students, 138(98.57\%) students agree that rural bond is beneficial because still health services are not available in many hard to reach areas they shows a positive approach of medical students towards bond, that students are aware of the problem of primary health care.

Only 46(32.85\%) students had knowledge about the extension of bond and 29(20.71\%) students knew about the procedure of extension, Similarly $40(28.57 \%)$ students knew about the procedure of exemption. We found that there is lack of knowledge about extention and exemption. Only $32(22.85 \%)$ students were willing to go for rural service after P.G. in case they opted for extention. it is argued that the result of the urban-based, specialized care and hospital centered model of medical education is that physician with any form of specialization were more likely to want to work in the private sector, and in urban areas. ${ }^{10}$ $40(28.57 \%)$ students agree with the government proposal in making the rural bond mandatory with no option for exemption.122(87.14\%) students think that by making rural bond mandatory the primary health service will improve.

\section{Conclusion}

As rural health is suffering from lack of health facilities so students should be posted in rural area for some time during their MBBS so they get 
sensitized to the rural health problem. Basic facilities and proper infrastructure is provided to the doctors posted in rural areas.

There is lack of knowledge about procedure of extension and exemption among students. Therefore students should be educated about these procedures at the time of admission or during the MBBS course.

\section{Recommendation}

There is a preference off home town should be given to all students before allocating them a PHC so they complete their bond. Basic facilities and proper infrastructure is provided to the doctors posted in rural areas.

\section{Limitation of the study}

1. The findings are based entirely upon the study conducted In 1 college of Indore city (MGM Medical College).

2. The time duration of study was limited,

3. The results are entirely based on answers given to the questionnaire, so there is possibility that some questions may be misinterpreted or intentionally wrongly answered.

\section{References}

1. SP Kalantri. Getting doctors to the village: will compulsion work .Indian journal of medical ethics (2017)

2. Meetajain, Shubhra agrawal Gupta, and Pritamroy: Attitude of would-be medical graduates toward rural health services, journal of family medicine and primary care 2016 Apr-Jun; 5(2): 440-443

3. Asvinidutt, Siddharudhashivalli, M. bhimabhat, Jagdish raopadubidri. Attitudes and perception towards rural health care service among medical students, medical journal of Dr.D.Y.Patil vidyapeeth 2014 Vol 7 Issue 6 Page 703-708
4. Dussault G, Franceschini MC. Not enough there, too many here: Understanding geographical imbalances in the distribution of the health workforce. Hum Resour Health. 2006;4:12. [PMC free article] [PubMed]

5. Deaville JA, Wynn-jones, Hays RB, Conentry PJ, Mckinley RK, Randall-Smith J.perception of UK medical students on rural clinical placements. Rural remote health 2009;9;1165

6. Lawson KA, Chew M, Van Der Weyden MB. A revolution in rural and remote Australia: Bringing health education to the bush. Med J Aust. 2000;173:618-24. [PubMed]

7. Saini NK, Sharma R, Roy R, Verma R. What impedes working in rural areas. A study of aspiring doctors in the National Capital Region, India? Rural Remote Health. 2012;12:1967.[PubMed]

8. Wilson NW, Couper ID, De Vries E, Reid $\mathrm{S}$, Fish T, Marais BJ. A critical review of interventions to redress the inequitable distribution of healthcare professionals to rural and remote areas. Rural Remote Health. 2009;9:1060. [PubMed]

9. Zaidi SA. Why medical students will not practice in rural areas: Evidence from a survey. SocSci Med. 1986;22:527-33. [PubMed]

10. Dussault G, Franceschini MC. Not enough, too many here: understanding geographical imbalance in the distribution of the health workforce. Hum Resour Health.2006;4:12[PMC freeartical] [PubMed] 